Initial knowledge states about assessment: novice teachers' conceptualisations

\author{
Introduction
}

The Issue

The reconceptualisation of educational assessment in recent years has not been in a vaccuum. During the 1990s it was becoming clear that, as the National Curriculum in England and Wales, and the 5-14 National Guidelines in Scotland became established, the systems for assessment which obtained were lacking in coherence and were limited in what they could contribute to:

- $\quad$ supporting learning, providing feedback to pupils, parents and other teachers, and identifying next steps in learning;

- providing information on which to monitor and evaluate provision and attainment at school, education authority and national levels.

While there has been improvement in the quality and use of assessment, there is still room for teachers to involve pupils in monitoring their own learning and to analyse assessment data with greater sophistication (HMIE, 2002; OFSTED, 2002). One powerful way in which teachers can begin to improve their assessment is for them to:

- be clear about the rationale which underpins their assessment practices

- appraise the claims they make in their rationale

- evaluate the significance of the empirical evidence on which the claims rest (Fenstermacher, 1986). 


\section{Initial knowledge states about assessment: novice teachers' conceptualisations}

In other words, it is not sufficient that teachers be procedurally skilled in implementing assessment (necessary as such skills are) but they must also be able to reason about their assessment practice. This reasoning, otherwise known as pedagogical reasoning, is an integral part of teaching and is founded on an extensive knowledge base (Shulman, 1987). Just as there is a relationship between knowledge of the substantive structure of the subject/discipline and effective teaching (Bennett \& Carré, 1993) so it seems reasonable to assume that knowledge of assessment will inform teachers' practice. One of the most robust findings in research on expertise is the strong relationship between knowledge and practice (Glaser, 1999). If a person's knowledg base influences that person's practice, it is worth considering what knowledge might be essential if beginning teachers are to assess children's work in ways that enhance learning. The focus of interest is therefore teachers' knowledge about assessment.

\section{The Shift in what Educational Assessment Means}

The shift from the historically dominant measurement model to the standards model (Berlak, 1992; Taylor, 1994) has seen earlier concerns with the relative, reliable performance of individuals on decontextualised, standardised tasks, give way to concerns about the extent to which assessment evidences thinking and problem-solving skills rather than discrete knowledge (Newmann and Archbald, 1992). The realisation that learning is not linear and atomistic and that it is not decontextualised, implies that the implementation of assessment necessarily involves a diverse range of tasks and procedures. No longer are tests of of some underlying unidimensional attribute seen as adequate instruments to ascertain educational achievement. Rather, portfolios and 


\section{Initial knowledge states about assessment: novice teachers' conceptualisations}

profiles, exhibitions of artefacts and performances as well as tests of discrete competencies each have the potential to evidence authentic academic achievement.

While the measurement model viewed assessment as an indicator of extant achievement, the standards model sees assessment as directly informing instruction (Nichols, 1994) and of itself representing meaningful, significant and worthwhile forms of human endeavour and accomplishment (Wiggins, 1989). Assessment is thus interactive since it underscores the processes of thinking and learning. Both learner and teacher explore the extent to which performance can be enhanced by effort or intervention. Because assessment is embedded in instructional episodes, learners learn from assessment when it models what performance is to be emulated and also indicates how to move towards more competent performance. But, for assessment to serve learning and teaching well, assessment tasks must evidence coherent and usable knowledge, principled problem solving and selfregulatory skills (Glaser, 1990). That assessment is now seen as having instructional value is a distinguishing criterion in the reconceptualisation of assessment.

Yet another feature in the reconceptualisation of assessment was the realisation that assessment is not value-neutral (Goldstein, 1993). At one level, the implications of this are fairly evident. If, by definition, assessment tasks are embedded in some social and political assumptions then it is not surprising that people of different social class, of different ethnicity, of different age or gender will respond differently to the tasks. Furthermore, because the assessment of what someone has learned is necessarily a process of inferring what internal processes give rise to the observed behaviour (since human competence is not directly observable or measurable), there is no absolute 


\section{Initial knowledge states about assessment: novice teachers' conceptualisations}

certainty that the relationship between the observed behaviour and the internal, unobservable process (or the construct) is valid. However, the stringencies of test construction within the psychometric paradigm mean that the technical matters of validity, reliability and the appropriate use of norms can result in the construct being very narrowly, or idiosyncratically defined, and in making a case for the test's construct validity the value judgements and subjective choices of the test constructors inevitably intervene (Messick, 1989). While the issue of the validity of the increasingly diverse range of educational assessments now used has not been resolved (Crooks, Kane \& Cohen, 1996), there seems to be awareness if not agreement that not only is it impossible to achieve consensus on what constitutes any cognitive competence but that it is undesirable in multicultural societies to deny plurality of perspective.

As the meaning and context of assessment becomes more elaborated, it seems important that teachers ground their practice in informed and rational decision-making. A necessary pre-requisite of this is a rich base of conceptual and metacognitive knowledge, which can be brought to bear in solving a problem. Because the knowledge that one possesses affects the type of understanding that one can construct about a domain as well as the types of problems that can be recognised and solved, the purpose of the study was to delineate knowledge-about-assessment; specifically to address the question, What do novice teachers know about assessment?

\section{Method}

Rationale In seeking to find out what novice teachers know about assessment, the superficially logical means of data collection, the interview, was discounted for three, 


\section{Initial knowledge states about assessment: novice teachers' conceptualisations}

tightly related reasons. Firstly, it is well known that interviews are susceptible to participant acquiescence and since this study sought the considered responses of the participants it was decided that a task requiring a prepared written response would better enable this. A second, reason for using a written task to elicit data was an acknowledgement of the evidence (Bereiter \& Scardamalia, 1987; Langer \& Applebee, 1987; Wells, 2002) that engagement in the writing process can enable the writer to transform extant and earlier understanding(s) into something more sophisticated. Hence the writing task was not merely a means of data collection but also a means through which participants could themselves learn (an opportunity, incidentally, that many participants explicitly acknowledged, in recognition of their own underveloped understandings of assessment). Thirdly, because of the ethical consideration not to use participants' time exclusively for the satisfaction of research purposes, course credit was attached to completion of the written task, although participation in the task was voluntary and alternative to other course requirements. The reasoning behind the written task was understood as contributing to its authenticity (Newmann \& Archbald, 1992) and thereby increasing the credibility which could be placed on the findings.

Design Written text on educational assessment was analysed using a category system derived by the author and informed by a range of writing on assessment (for example, Berlak, 1992; Black \& Wiliam, 1998; Messick, 1989; Newmann \& Archbald, 1992; Taylor, 1994) Further, Shulman's (1987) emphasis on the significance of the knowledge base provided the conceptual foundation for the category system. Knowledge of assessment was taken to mean knowledge of principles and methods. Assessment principles include: 


\section{Initial knowledge states about assessment: novice teachers' conceptualisations}

- clear purpose (such as diagnosing or aiding learning, evaluating teaching, motivating learners or ranking,selecting and grading learners);

- the basis for comparison (usually taken to mean normative or criterial but can also include ipsative);

- modes (emphasis and timing) of assessment (which are represented as bipolar dimensions such as informal/formal, process/product, formative/summative);

- fairness (now perhaps better understood as 'just' or 'equitable' assessment but in any event relying on the precepts of validity and reliability);

- $\quad$ source of assessment (self, peer or teacher/other).

Assessment methods refer to the instruments through which information is gathered and would include:

- tests (objective measures designed to yield a 'correct answer' and which might be constructed by the teacher or some external body, may/not be standardised, may be national or local);

- open-ended writing (which may be short, long or extended and in which the respondent has some choice as to how the piece of writing is formulated);

- the creation of some artefact or performance which can be observed by others;

- oral work (which might be a formal presentation, particpation in discussion with teacher and/or learners, proficiency in discussion or some consultation type task).

Participants Participants were enrolled in the Education Faculty of a Scottish university for a 36-week, full-time course of study in primary education, the successful completion 


\section{Initial knowledge states about assessment: novice teachers' conceptualisations}

of which results in the award of a postgraduate certificate in primary education.

Possession of this certificate is one of the two principal ways through which teachers can gain provisional registration with The General Teaching Council in Scotland, enabling them to teach across the seven years of primary education and through all five areas of the curriculum (Mathematics, Language, Environmental Studies, Expressive Arts and Religious/Moral education). Most of the participants were completing the course to enable career changes and so brought to the course a very wide range of vocational experiences, although any teaching experience had been of an informal nature only. The average age of the 23 female and 7 male participants was 35 years. Twenty seven of the participants were United Kingdom nationals while the remaining 3 were Canadian. At the time of engaging in the study described here, the participants had completed 18 weeks of field experience and 12 weeks of in-Faculty study and so were almost at the point of applying for licensure.

Output for analysis Thirty essay scripts, of 3500-4000 words from teacher-education students in response to the question, 'What do you know about educational assessment that will help you in your teaching?' were content analysed.

Analysis The essays comprised the sampling units for the analysis. The unit of analysis was the paragraph since it is a distinct section of discourse dealing with a particular point, topic or theme. Paragraphs were not all of equal size. Paragraphs were read for their topic sentence and coded accordingly. Independent coding by two coders on a sample of 10 scripts suggested that the stability of the coding procedure was acceptable with kappa coefficients being 0.88 . Only those paragraphs that contained 


\section{Initial knowledge states about assessment: novice teachers' conceptualisations}

reference to assessment methods or principles (as defined above) were coded.

Paragraphs which evidenced no knowledge of assessment principles or methods were discounted because:

they were 'signposting' the progress of the essay as in:

In order to consider the topic of assessment, it is necessary to consider the ways in which children learn, what makes learning effective and how we determine the effectiveness of our teaching.

they were discussing learning theory per se rather than knowledge of assessment as in:

Two key schools of thought exist regarding the process of learning. Behaviourism focused on that which was observable and measurable. Drawing heavily on Skinner, behaviourism claimed that there was no reason to suppose that the laws which governed observable behaviour should not also govern activity in the mind. In counterpoint to behaviourism, theories relating to cognitivism emerged much later. Influenced initially by Piaget, cognitive explanations of learning considered internal processing and the individual's construction of meaning more important.

they were rehearsing some cant which did not illuminate assessment as in:

Assessment must not be allowed to dominate the teacher's time in the classroom. Assessment must also be controlled and not be allowed to become over powering 


\section{Initial knowledge states about assessment: novice teachers' conceptualisations}

which could lead the teacher to focus more time on maths and language at the expense of other subjects.

\section{Results}

Insert Table I about here, please.

Knowledge of assessment was reflected variously. Table 1 summarises the number of paragraphs in each essay that were concerned with assessment knowledge. In terms of assessment principles, all participants made at least some reference to the purpose and modes of assessment, 24 made reference to the source of assessment whilst the basis on which to interpret assessment results and the fairness of assessment were mentioned by only 12 and 15 participants respectively. In terms of assessment methods, 16 participants referred to what would be categorised as tests, 10 to the production of artefacts or performances and 15 to oral methods, but only 7 participants made any reference to written methods of assessment. The paragraphs themselves are not comparable because they are of variable number across scripts and of variable length within scripts; presumably because particiapants' schemata or mental representations of the different elements of knowledge-about-assessment vary considerably (Rumelhart, 1980) and have fuzzy boundaries (Rosch, 1973). However, the quantification of paragraphs shows the relative emphasis given to the different elements of assessment knowledge within any one script and to the elements of knowledge which did/did not seem to be included. It is the nature of the knowledge across scripts which is of particular interest in this study and will be used as the basis of the discussion. 


\section{Initial knowledge states about assessment: novice teachers' conceptualisations}

\section{Discussion}

The study reported here was seeking to answer to the question, What do novice teachers know about assessment?

Knowledge of Assessment Principles

While Table I shows variability in the knowledge of assessment principles evidenced, there are some discernible consistencies. A first consistency was in the purpose of assessment. All participants acknowledged that assessment information could be used for accountability and for supporting learning. This knowledge was offered as factual and, while possibly dichotomous, was relatively uncontentious as the following extract shows:

Assessment serves a variety of purposes in education today. It is used for certification and selection of pupils for admission to higher education institutions. It is also used to monitor standards in schools and to allow comparison to be made between schools. Until fairly recently, the majority of assessment research focussed on these summative purposes of assessment. However, assessment also plays a vital role in teaching and learning. It enables teachers to diagnose pupil difficulties, enhance pupil motivation, evaluate their teaching and plan the next teaching and learning steps to be taken.

Such tension as was perceived about the purposes of assessment was represented more as an irritating obstacle than as a cultural reality: 


\section{Initial knowledge states about assessment: novice teachers' conceptualisations}

The purpose of norm-referenced assessment does not benefit the learner in any significant way other than to create criteria for national standards. Normreferenced assessment should be discontinued.

Offerings of this type did not recognise that the purpose of assessment has implications for what type of assessment is conducted nor did it acknowledge that there might be some common but qualified ground between different purposes (Brown, 2002; Kimball \& Cone, 2002; McLain, 2002; Sirotnik, 2002).

A second consistency was in the emphasis and timing of assessment. All participants acknowledged the formative-summative mode (and a few made brief reference to other modes):

Summative assessment is testing or examining in a formal situation, usuually carried out at the end of a programme of work, and is a judgement of standard achieved. Formative assessment is something that exists in day-to-day classroom practice. Its main aim is to collect short term evidence that will promote further learning for the pupils in a class. It is carried out by teachers themselves and involves them in diagnosing problems, recognising achievements and giving useful feedback to individuals as well as informing future planning for teaching.

While some participants did recognise that formative assesment per se might be problematic, they largely perceived the formative mode as more important than the summative mode, a distinction which is reflected in the literature (Buckendahl, Impara, \& Plake, 2001; Kyriakides \& Campbell, 1999; Yorke, 2001). A few even attempted some 


\section{Initial knowledge states about assessment: novice teachers' conceptualisations}

exploration of the relationship between formative and summative functions (Wiliam \& Black, 1996; Harlen \& James, 1997), but while these explorations drew out the confusion in understanding each of the poles, they did not convincingly resolve how assessment data gathered in one mode might be properly interpreted in the other. Many of the participants used the formative-summative mode as a structuring device round which they made connections to other aspects of assessments and thereby produced scripts which gave some impression of global coherence. A few participants made connections between the formative mode and constructivist perspectives on learning to offer a persuasive case for the process of assessment having an impact on pupils but these were outnumbered by the many who uncritically suggested that formative feedback can and will enable the teacher to promote learning (Torrance and Pryor, 1998).

As a consequence of their awarenesss of formative assessment, many participants acknowledged that not only was the teacher a sourceof assessment but so too were the pupils themselves. In recognising the teacher's responsibility in assessment, extracts such as the following were common:

Working within a formative framework allows teachers to identify achievements. As a result, teachers are in an improved position to identify individual differences in learning and differentiate according to the needs of individual pupils. It is the provision of freedback within this cycle of diagnosis and differentiation that can lead to the promotion of learning. However the quality of this feedback plays a significant role in the extent to which assessment will cause further learning. 


\section{Initial knowledge states about assessment: novice teachers' conceptualisations}

It was clear from just about all of the scripts that the teacher's role in assessment was a 'top-down' one in which he/she made few, if any, assessment decisions in consultation with pupils. Such a conception of the teacher's role is now seen as outdated (Hackelton, 2002; Keefe \& Jenkins, 2002; Miller \& Byrnes, 2001; Wiener \& Cohen,. 2002;). Of the scripts which recognised the role of le arners in their own assessment (and the majority did), the following excerpt was perhaps the most sophisticated representation of the importance of self-assessment:

Cognitive theories suggest that the child must be fuly engaged in what is being taught before learning will take place. For this to happen, children must know what is expected of them, how to achieve the expectation and why. It is therefore important that children receive qualitative written and oral feedback in order that they can appreciate how well they are doing and how they can improve.

while the excerpt immediately below would be more typical:

By communicating the aims of learning, teachers can include pupils in identifying where they are now in relation to learning goals, to encourage them to take responsibility for moving forward.

While those scripts which acknowledged self-assessment generally recognised that different types of feedback can significantly affect subsequent learning (Butler, 1987; Dweck, 2000; Kluger \& DeNisi, 1996), they did not consider how to implement self assessment as indicated by Black \& Wiliam's (1998) review. This meant that issues involved in pupils' access to assessment criteria or to exemplars of aceptable standards, in 


\section{Initial knowledge states about assessment: novice teachers' conceptualisations}

self-designed assessment tasks, or in pupils themselves driving formative assessment were not acknowledged in any of the scripts. At best, then self-assessment was viewed as a bonus of formative assessment without any appreciation of its centrality in the metacognitive management of one's own learning.

The remaining consistency in novice teachers' knowledge of assessment principles was in their scant acknowledgement for either the basis of comparison on which judgements are made or for the issues of reliability and validity in assessment. True, there were assertions along the lines of:

Assessment must be valid and reliable.

or

Assessment can be norm-referenced or criterion-referenced.

However, because there was little (and often no) exemplification or elaboration of the concepts in either type of assertion, such knowledge as the participants did have was not networked to any of their other knowledge about assessment and so was inert. For example, while there was no expectation that scripts would evidence technical exposition on all aspects of validity, knowledge of the principle of 'fair' assessment would have been more convincing had there been even some awareness of content validity and consequential validity (Messick, 1989). Similarly, participants' knowledge of the distinction between norm-referenced and criterion-referenced asessment would have been more convincing had there been some acknowledgement of distinctions between the assessment of aptitude (or cognitive process) and the assessment of achievement (or 


\section{Initial knowledge states about assessment: novice teachers' conceptualisations}

cognitive product) and of the role of learning in relation to both (Good \& Brophy, 1986;

Popham, 1974; Thorndike, 1997).

\section{Knowledge of Assessment Methods}

Inspection of Table I also shows variability in participants' knowledge although the overall finding is that the participants evidenced little explicit knowledge of assessment methods. References to tests acknowledged the country-wide policy of national testing and the commonly held view that tests are perhaps best fitted for assessing the acquisition of factual knowledge. There was also some confusion as to whether the national tests in Scotland were standardised. It was interpreted as somewhat strange that those who did refer to tests did not consider the type of objective measure used since they were at least familiar with, if not practised in, designing and using worksheets for pupils in which the tasks were multiple-choice items, short-answer completions, dichotomous-choice items or matching items. However, while the participants were not unfamiliar with constructing such workshheets, they did not appear to explicitly recognise this as assessment. Such references as there were to tests failed to suggest criteria by which the quality of a test might be judged, how to write test questions or develop a test, how to administer a test efficiently and fairly or to recognise the issues surrounding test score interpretation. This lack of essential knowledge (Ebel, 1961) pessimistically suggests that novice teachers are ill equipped to competently assess pupils in their charge (Hopkins, 1998).

There was no explicit acknowledgement that short or extended written work might allow pupils to deonstrate higher-order thinking skills or, indeed, any originality in their 


\section{Initial knowledge states about assessment: novice teachers' conceptualisations}

thinking. Such acknowledgement as there was recognised that some observed pieces of written work were invalid either because their contents were not sampling, or because the requirements of the written medium were conflated with, the construct under assessment. A lack of regard for the value of written work as a possible means of assessing authentic academic achievement (Newmann \& Archbald, 1992) could be inferred from all of the scripts which made reference to methods of assessment, but was particularly striking in scripts which characterised national tests as being pedagogically unhelpful because they allegedly assessed nothing more than factual information. In other words, while scripts made reference to the importance of learning-as-understanding, concern with how such learning might be evidenced did not include written work. Perhaps, however, belief in the importance of written work as evidence of tranformative learning (Bereiter \& Scardamalia, 1987) is being compromised by confusions in understanding the extent to which authentic tasks are 'performances' that are valued in the adult world and tasks that focus on the production of knowledge (Newmann \& Archbald, 1992; Ottobre, 1999).

A very small number of participants made reference to 'practical' assessment, to the observation of some artefact or performance (usually in the curriculum area of physical education and reflected in statements such as the ability to perform a handstand can only be assessed by observation or you can't assess a forward role by giving the children a test). Apart from the participant's omission of any consideration of the validity of observation schedules per se (Thorndike, 1997), the references to artefact or performance assessment did not grapple with the esential point of whether such assessment is taskcentred or construct-centred (Messick, 1994). While it can be inferred from participants' statements that the performances they are observing are task-centred (insofar as the target 


\section{Initial knowledge states about assessment: novice teachers' conceptualisations}

of the assessment is the performance per se), their lack of consideration of the possibility that another type of performance might be construct-centred stongly suggests that they do not connect issues of replicability and generalisability (and therefore of the issues of reliability and validity) with assessment method.

The final assessment method to be discussed is oral work. Unfailingly, those participants who referred to this method conceptualised it only in terms of teachers asking questions of pupils. Although this focus was very narrow, and so ignored key issues in oral work such as communicating a body of information to an audience, handling and facilitating questions/discussion and self-presentation through voice and body language, the participants were nevertheless clear that constructing higher-order questions was more difficult than constructing questions of recall (Black, \& Harrison, 2001; Wilen, 2001; Wimer, Ridenour, Thomas \& Place, 2001), and that planning out questions in advance in order to stimulate higher-order thinking was probably important (Lenski, 2001, Wood, \& Anderson, 2001).

\section{Significance of the Findings}

While knowledge-about-assessment is a large and complex field, it is evident from this study that particpants displayed limited knowledge of both assessment principles and methods. Further, such knowledge as participants displayed was largely compartmentalised so although they saw the formative-summative mode of assessment as a meaningful framework within which to represent analysis and discussion on the role of educational assessment, the connections made between this mode of assessment and the other principles of assessment such as purpose(s) of assessment, the basis for comparison 


\section{Initial knowledge states about assessment: novice teachers' conceptualisations}

and fair assessment were not well developed. Similarly while a good number of participants saw some relationship between mode and source of assessment, their expositions on the relationship were far from complete. This lack of integrated knowledge is evident in advanced students of other disciplines (for example, Boshuizen, Schmidt, Custers \& Van de Wiel, 1995; Hofer \& Pintrich, 1997) and suggests that while there has been some accretion of knowledge, there has been no restructuring (Rumelhart \& Norman, 1978). This in turn indicates that the learning about assessment that has taken place is still at a very unsophisticated stage (Shuell, 1986; 1990) and raises the important question of how ready the participants - novice teachers about to become provisionally licensed - were to make autonomous professional judgements about pupils' learning.

Participants in this study frequently acknowledged that their knowledge about assessment had hitherto been circumscribed by their own experiences, usually of summative and terminal assessment for accountability purposes. And so what they had now learned represented considerable progress in developing their knowledge. However, laudable as such progress may be it is not enough. Since the fundamental rationale for a more elaborated conception of educational assessment is that teachers can better facilitate pupil learning, they must simultaneously consider a range of assessment principles and methods and make connections between and among them (Sergiovanni \& Starrat, 1995). Novice teachers are thus faced with a formidable task. They have to develop a level of cognitive complexity about assessment (through both the accretion and restructuring of knowledge-about-assessment) which is beyond the concepts and procedures they 


\section{Initial knowledge states about assessment: novice teachers' conceptualisations}

currently have for application. This phenomenon is what Bereiter (1985) refers to as the learning paradox.

\section{What might be done?}

Because there is considerable hard evidence which points to both the importance and cognitive advantages of a well-developed knowledge base (Haskell, 2001), teacher education is faced with the pedagogical problem of how to enable students to overcome their knowledge deficits. Courses of professional preparation must recognise that while additive learning is important, learning that involves an increase in structural complexity is also (and maybe more) important because it allows more profound reasoning. Insights derived from findings in cognitive science suggest that to promote complex learning, tutors might pay renewed attention to the the role of the learner and the role of reading.

The role of the learner In the literature there is no real resistance to the idea that humans are fundamentally knowledge constructors. What is much less explicit is what a pedagogy derived from constructivism might look like. One fundamental point is emerging, however: it is the learners themselves who must communicate, justify and defend their ideas since this is the essence of their being active learners. Tutors can support learners in this endeavour in a variety of ways but it is what learners themselves do that is the critical factor in determing what and if they learn (Shuell, 1986). A further dimension to the centrality of the learner's role is the learner's engagement in goaldirected behaviour. Not only does the learner address the immediate requirements of the task but extrapolates from the specific task to reflect on its contribution to the learner's competence and understanding. This engagement is known as intentional learning, 


\section{Initial knowledge states about assessment: novice teachers' conceptualisations}

evident in those who view learning as a goal to be achieved rather than an activity to be enacted (Bereiter \& Scardamalia, 1989). The primacy of the learner thus suggests, counterintuitively, that learning tasks, rather than being overly strucured by tutors to minimise the possibility of learner error, might be more useful if they were complex or difficult since expertise does not develop through doing only what is within one's competence but through working on real problems that require the extension of knowledge and competence (Scardamalia \& Bereiter, 1991). At a pragmatic level, it might also be helpful to focus on a few significant learning tasks for which the learners are accountable, and thereby communicate to the learners the kind of intellectual work which is valued (Crooks, 1988; Gibbs, 1999; Ramsden, 1997), rather than having a multitude of learning tasks which may have little or no alignment with the desired learning outcomes (Biggs, 1999). For example, it would seem important that tutors give primacy to the need for students to conceptualise new knowledge about assessment and so in an iterative fashion, tasks that require the comprehension, transformation and expansion of knowledge about assessment (Sarig, 1996) might better enable students to appreciate that the analyses of, and solutions to, problems of assessment are real and immediate issues with which they have to grapple in their professional practice. The essential point in all of this is that it is only when learners in the formal educational system are required to construct or generate their own new knowledge (Newmann \& Archbald, 1992) that they will seriously grapple with significant learning.

The role of reading The findings in this study suggest that the participants' situation models (Kintsch, 1998) of assessment comprised compartmentalised and partial knowledge of principles and methods. In order that the situation model can fulfil its 


\section{Initial knowledge states about assessment: novice teachers' conceptualisations}

purpose of enabling the person to solve problems or effect appropriate action (which in this case would mean addressing the many problems of classroom assessment that practising teachers eperience), it is assumed that the individual is behaving as though he/she is inside a particular situation rather than outside of it (Zwann, 1999). Therefore it would seem important that student teachers become aware of their own understanding of assessment through deliberating on, and sharing insights into, problems involving assessment. Having identified, for example, issues round the experiences of being assessed, the teacher's role and responsibility in assessment, the design of assessment, and the relationship between assessment and learning, student teachers could then pursue these issues through further reading. Not only would such expository text contribute to the reader's knowledge of the topic in question, but, more importantly, the semantic content of the reading, the reader's extant knowledge of assessment that is triggered by the text, the inferences that the reader derives from the text, the reader's recognition of the issue or problem that precipitated the reading in the first place, together with any other conceptual knowledge which the reader can retrieve from memory as being pertinent enables the construction of a more advanced situation model. While far from straightforward, the process of reading as developed by Kintsch (1998) is clearly powerful and offers a framework for describing how understanding is facilitated or constrained. The importance of consrtucting a situation model, even a partial one, which is then elaborated through further reading cannot therefore be overstated, becaue without a situation model the reader can neither evaluate the information in the text nor effect appropriate action in respect of assessment. In other words no substantive learning has taken place. What this implies in the context of the present study is that professional 


\section{Initial knowledge states about assessment: novice teachers' conceptualisations}

preparation makes more, not less, reading demand of teachers. Novice teachers need to read to extend their domain knowledge about assessment so that they do not rely merely on common-sense knowledge. However, even high exposure to develop a rich domain of knowledge is, of itself, not enough. Such knowledge must be capable of being used in the practice of assessment. For the knowledge to be usable, novice teachers must build situation models of assessment practice through consciously invoking cognitive, strategic behaviour to remember, make sense of, or reconfigure new information. It is they who must make inferences from their reading, determine and overtake the gaps in their knowledge base, and make connections among the various pieces of of knowledge-aboutassessment which are conceptually isolated. To support learners in creating situation models, Kintsch (1998) has had some success using poorly written text which forces learners to compensate for text lacking in coherence. Such a suggestion is consistent with the case put forward earlier, for learners being required to grapple with complex, big or fuzzy ideas.

While it is not possible to determine the extent to which the role of the learner and the role of reading were emphasised in the course from which the participants in this study were drawn, the cognitive science literature reminds us that if novice teachers need to engage in complex learning (which has been argued here as being important), course design and delivery needs to be congruent with the idea that important learner activity is the sort of cognitive effort outlined above. 
Initial knowledge states about assessment: novice teachers' conceptualisations

\section{Conclusion}

The findings reported here suggest that novice teachers' knowledge about assessment is underdeveloped and thus detrimental to more profound reasoning about assessment practice, which is argued to be increasingly important as the construct of assessment itself becomes more elaborated. The nature of novice teachers' knowledge would imply that teacher education should pay more attention to enabling student teachers to develop greater cognitive complexity in their thinking about assessment. For this to happen they must be actively engaged in promoting their own learning through engaging in difficult tasks and must interact frequently and systematically with reading material which will enlarge their domain knowledge of assessment. 


\section{References}

Bennett, N. \& Carré, C. (1993). Learning to Teach. London: Routledge.

Berlak, H. (1992). The need for a new science of assessment. In H. Berlak, F. Newmann, E. Adams, D. Archbald, T.Burgess, J. Raven, \& T. Romberg (Eds.), Towards a New Science of Educational Testing and Assessment. New York: State University of New York Press.

Bereiter, C. (1985). Toward a solution of the learning paradox. Review of Educational Research, 55(2), 201-6.

Bereiter, C. \& Scardamalia, M. (1987). The Psychology of Written Composition. NJ: Lawrence Erlbaum Associates.

Bereiter, C. \& Scardamalia, M. (1989). Intentional learning as a goal of instruction. In L. Resnick (Ed.), Knowledge, Learning and Instruction. Hillsdale, New Jersey: Lawrence Erlbaum Associates.

Biggs, J. (1999). Teaching for Quality Learning at University. Buckingham: The Society for Research into Higher Education \&The Open University Press.

Black, P. \& Harrison, C. (2001). Feedback in questioning and marking: the science teacher's role in formative assessment. School Science Review, 82(301), 55-61.

Black, P. \& Wiliam, D. (1998). Assessment and classroom learning. Assessment in Education, 5 (1), 7-74. 


\section{Initial knowledge states about assessment: novice teachers' conceptualisations}

Boshuizen, H., Schmidt, H., Custers, E. \& Van de Wiel, M. (1995). Knowledge development and restructuring in the domain of medicine: the role of theory and practice. Learning and Instruction 5, 269-89.

Brown, J. (2002). The portfolio: a tool for workplace learning and development. Paper presented at the National Meeting of the American Educational Research Association. New Orleans: LA, April 1-5.

Buckendahl, C., Impara, J. \& Plake, B. (2001). A Strategy for Evaluating District Developed Assessments for State Accountability. Paper presented at the Annual Meeting of the MidWestern Educational Research Association. Chicago, IL, October 24-27.

Butler, R. (1987). Task-involving and ego-involving properties of evaluation. Journal of Educational Psychology, 79(4), 474-82.

Crooks, T. (1988). The impact of classroom evaluation practices on students. Review of Educational Research, 58 (4), 438-81.

Crooks, T., Kane, M. \& Cohen, A (1996). Threats to the valid use of assessment. Assessment in Education, 3(3), 265-285.

Dweck, C. (2000). Self-Theories. Hove: East Sussex: Psychology Press.

Ebel, R. (1961). Improving the competence of teachers in educational measurement. Clearing House, 36, 67-71. 


\section{Initial knowledge states about assessment: novice teachers' conceptualisations}

Fenstermacher, G. (1986). Philosophy of research on teaching. In M. Wittrock (Ed.), Handbook of Research on Teaching. New York: Macmillan.

Gibbs, G. (1999). Using assessment strategically to change the way students learn. In S. Brown \& A. Glasner (Eds.), Assessment Matters in Higher Education. Buckingham: The Society for Research into Higher Education \& The Open University Press.

Glaser, R. (1990). Toward new models for assessment. International Journal of Educational Research, 14(5), 475-83.

Glaser, R. (1999). Expert knowledge and processes of thinking. In R. McCormick \& C Paechter (Eds.), Learning and Knowledge. London: Paul Chapman Publishing in association with The Open University Press.

Goldstein, H. (1993). Assessing group differences. Oxford Review of Education, 19(2), 141-150.

Good, T. \& Brophy, G. (1986). Educational Psychology. New York: Longman.

Hackelton, D. (2002). The Authority of the teacher in the student-centered classes. Paper presented at the Annual Meeting of the Conference on College Composition and Communication (53rd, Chicago, IL, March 20-23).

Harlen, W. \& James, M. (1997). Assessment and learning:differences and relationships between formative and summative assessment. Assessment in Education, 4(3), 365-79.

Haskell, R. (2001). Transfer of Learning London: Academic Press. 


\section{Initial knowledge states about assessment: novice teachers' conceptualisations}

Her Majesty's Inspectorate of Education (HMIE) (2002). Standards and Quality in Primary and Secondary Schools: 1998-2001 Edinburgh: Her Majesty's Stationery Office.

Hofer, B. \& Pintrich, P. (1997). The development of epistemological theories: beliefs about knowledge and knowing and their relation to learning. Review of Educational Research, 67(1) 88-140.

Hopkins, K. (1998). Educational and Psychological Measurement and Evaluation. London: Allyn \& Bacon.

Keefe, J. \& Jenkins, J. (2002). Personalized instruction. Phi Delta Kappan; 83 (6), 440-48

Kimball, C. \& Cone, T. (2002). Performance assessment in real time. School Administrator, 4(59), 14-16.

Kintsch, W. (1998). Comprehension. Cambridge: Cambridge University Press.

Kluger, A. \& DeNisi, A. (1996). The effects of feedback intervention on performance. Psychological Bulletin, 119(2), 254-84.

Kyriakides, L. \& Campbell, R. (1999). Primary teachers' perceptions of baseline assessment in mathematics. Studies in Educational Evaluation, 25(2), 109-30.

Langer, J. \& Applebee, A.(1987). How Writing Shapes Thinking. Urbana, IL: National Council of Teachers of English.

Lenski, S. (2001). Intertextual connections during discussions about literature. Reading Psychology, 22(4), 313-35. 


\section{Initial knowledge states about assessment: novice teachers' conceptualisations}

McLain, B. (2002). Strategies to engage students in learning. Paper presented at the National Meeting of the American Educational Research Association (New Orleans, LA, April 1$5)$.

Messick, S. (1989). Validity. In R. Linn (Ed.), Educational Measurement ( ${ }^{\text {rd }}$ edition). New York: American Council on Education and Macmillan.

Messick, S. (1994). The interplay of evidence and consequences in the validation of performance assessments. Educational Researcher, 23(2), 13-23.

Miller, D. \& Byrnes, J. (2001). To achieve or not to achieve: a self-regulation perspective on adolescents' academic decision making. Journal of Educational Psychology; 93(4), 67785.

Newmann, F. \& Archbald, D. (1992). The nature of authentic academic achievement. In H. Berlak, F. Newmann, E. Adams, D. Archbald, T. Burgess, J. Raven, \& T. Romberg (Eds.), Towards a New Science of Educational Testing and Assessment. New York: State University of New York Press.

Nichols, P. (1994). A framework for developing cognitively diagnostic assessments. Review of Educational Research, 64(4), 575-603.

Office for Standards in Education (OFSTED) (2002). Standards and Quality in Education 2000/01: The Annual Report of Her Majesty's Chief Inspector of Schools. London: The Stationery Office. 


\section{Initial knowledge states about assessment: novice teachers' conceptualisations}

Ottobre, F. (1999). The role of measurement and evaluation in education policy. Paris: UNESCO Publishing.

Popham, W. (1974). An approaching peril: cloud-referenced tests. Phi Delta Kappan, 55(9), 6145.

Ramsden, P. (1997). The context of learning in academic departments. In F. Marton, D. Hounsell, \&. N. Entwistle, (Eds.), The Experience of Learning. Edinburgh: Scottish Academic Press.

Rosch, E. (1973). Natural categories, Cognitive Psychology, 4, 328-50.

Rumelhart, D. \& Norman, D. (1978). Accretion, tuning and restructuring: three modes of learning. In R. Klatzky \& J. Cotton (Eds.), Semantic Factors in Cognition (pp. 37-52) Hillsdale, New Jersey: Lawrence Erlbaum Associates.

Rumelhart, D. (1980). Schemata: the building blocks of cognition. In R. Spiro, B. Bruce \& W. Brewer (Eds.), Theoretical Issues in Reading Comprehension. Hillsdale, New Jersey: Lawrence Erlbaum Associates.

Sarig, G (1996) Assessment of academic literacy. In M. Birenbaum \& F. Dochy (Eds.), Alternatives in Assessment of Achievements, Learning Processes and Prior Knowledge. Dordrecht, Kluwer Academic Press.

Scardamalia, M. \& Bereiter, C. (1991). Literate expertise. In K. Anders Ericsson \& J. Smith (Eds.), Toward a General Theory of Expertise (pp. 173-94). Cambridge: Cambridge University Press. 


\section{Initial knowledge states about assessment: novice teachers' conceptualisations}

Sergiovanni T. \& Starrat, R. (1995). Supervision. New York: McGraw-Hill.

Sirotnik, K. (2002). Promoting responsible accountability in schools and education, Phi Delta Kappan, 83(9), 662-73.

Shuell, T. (1986). Cognitive conceptions of learning, Review of Educational Research, 56(4) 411-36.

Shuell, T. (1990). Phases of meaningful learning. Review of Educational Research, 60(4), 53147.

Shulman, L. (1987). Knowledge and teaching: foundations of the new reform. Harvard Educational Review, 57(1), 1-22.

Taylor, C. (1994). Assessment for measurement or standards: the peril and the promise of large scale assessment reform. American Educational Research Journal, 31(2), 231-62.

Thorndike, R. (1997). Measurement and Evaluation in Psychology and Education. New Jersey: Prentice-Hall Inc.

Torrance, H. \& Pryor, J. (1998). Investigating Formative Assessment. Buckingham: Open University Press.

Wells, G. (2002). Learning and teaching for understanding: the key role of collaborative knowledge building. In J. Brophy (Ed.), Social Constructivist Teaching: Affordances and Constraints (pp 1-41). Oxford: Elsevier Science. 


\section{Initial knowledge states about assessment: novice teachers' conceptualisations}

Wiener, R. \& Cohen, J. (2002). New paradigms for familiar concepts: portfolios and conferencing as performance based assessment tools. Journal of Early Education and Family Review, 9(3), 8-16.

Wiggins, G. (1989). Teaching to the (authentic) test. Educational Leadership, 46(7), 41-47.

Wilen, W. (2001). Exploring myths about teacher questioning in the social studies classroom. Social Studies, 92(1), 26-32.

Wiliam, D. \& Black, P. (1996). Meanings and consequences a basis for distinguishing formative and summative functions of assessment? British Educational Research Journal, 22(5), $537-48$.

Wimer, J., Ridenour, C., Thomas, K. \& Place, W. (2001). Higher order teacher questioning of boys and girls in elementary mathematics classrooms. Journal of Educational Research; 95(2), 84-92.

Wood, A. \& Anderson, C. (2001).The case study method: critical thinking enhanced by effective teacher questioning skills. Paper presented at the Annual International Conference of the World Association for Case Method Research \& Application (Sweden, June 17-20).

Yorke, M. (2001). Turn first-semester assessments into richer learning experiences. Innovations in Education and Teaching International; 38(3), 277-78.

Zwann, R. (1999) Situation models: the mental leap into imagined worlds. Current Directions in Psychological Science, 8(1) 15-18 
Initial knowledge states about assessment: novice teachers' conceptualisations

\section{RESULTS}

$\underline{\text { Table I Knowledge of Principles and Methods }}$

\begin{tabular}{|c|c|c|c|c|c|c|c|c|c|}
\hline \multirow[t]{2}{*}{$\begin{array}{l}\text { CASE(no. } \\
\text { of paras) }\end{array}$} & \multicolumn{5}{|c|}{$\begin{array}{l}\text { KNOWLEDGE OF PRINCIPLES(number of } \\
\text { paragraphs) }\end{array}$} & \multicolumn{4}{|c|}{$\begin{array}{l}\text { KNOWLEDGE OF } \\
\text { METHODS(number of } \\
\text { paragraphs) }\end{array}$} \\
\hline & purpose & $\begin{array}{l}\text { basis for } \\
\text { comparing }\end{array}$ & mode & fairness & source & tests & writing & art/perfs & oral \\
\hline $1(32)$ & 6 & 2 & 11 & 3 & 6 & 1 & - & 1 & 2 \\
\hline $2(23)$ & 5 & - & 9 & - & 5 & 2 & - & - & 2 \\
\hline $3(11)$ & 3 & - & 7 & - & - & 1 & - & - & - \\
\hline $4(9)$ & 1 & 1 & 4 & 1 & 2 & - & - & - & - \\
\hline $5(21)$ & 4 & 2 & 12 & - & - & 1 & - & 1 & 1 \\
\hline $6(17)$ & 4 & - & 12 & - & 1 & - & - & - & - \\
\hline $7(17)$ & 1 & 4 & 10 & - & 1 & 1 & - & - & - \\
\hline $8(15)$ & 2 & 1 & 6 & 1 & 3 & - & - & 1 & 1 \\
\hline $9(30)$ & 7 & - & 15 & 4 & 4 & - & - & - & - \\
\hline $10(9)$ & 2 & - & 6 & - & 1 & - & - & - & - \\
\hline $11(25)$ & 3 & 2 & 12 & 6 & 2 & - & - & - & - \\
\hline $12(17)$ & 3 & - & 9 & 3 & - & - & - & - & 2 \\
\hline $13(15)$ & 4 & - & 8 & 1 & 1 & 1 & - & - & - \\
\hline $14(27)$ & 4 & - & 16 & - & 3 & 1 & 1 & - & 2 \\
\hline $15(18)$ & 2 & - & 10 & - & 1 & 1 & 1 & - & 3 \\
\hline $16(26)$ & 3 & - & 17 & 1 & 1 & 1 & 1 & - & 2 \\
\hline $17(19)$ & 4 & - & 11 & 1 & 1 & - & 1 & 1 & - \\
\hline $18(24)$ & 5 & - & 11 & - & 2 & 2 & 1 & 1 & 2 \\
\hline $19(11)$ & 2 & - & 8 & - & - & - & 1 & - & - \\
\hline $20(18)$ & 3 & - & 10 & - & 4 & 1 & - & - & - \\
\hline $21(20)$ & 4 & - & 14 & - & 2 & - & - & - & - \\
\hline $22(17)$ & 2 & 1 & 7 & 1 & 2 & 2 & - & 1 & 1 \\
\hline $23(18)$ & 3 & 1 & 11 & 1 & - & - & - & 1 & 1 \\
\hline $24(15)$ & 2 & 1 & 8 & 1 & 1 & 1 & - & 1 & - \\
\hline 25 (19) & 2 & 2 & 10 & 1 & - & 3 & - & - & - \\
\hline $26(24)$ & 1 & 3 & 14 & 1 & 2 & - & - & - & 3 \\
\hline 27 (19) & 3 & 2 & 9 & 1 & 1 & - & 1 & - & 2 \\
\hline $28(20)$ & 3 & - & 12 & - & 1 & 1 & - & 1 & 2 \\
\hline $29(16)$ & 3 & - & 10 & - & 3 & - & - & - & - \\
\hline $30(14)$ & 1 & - & 8 & - & 2 & 1 & - & 1 & 1 \\
\hline
\end{tabular}

